Original Research Article

\title{
In Silico Anti-Inflammation Prediction of Glycyrrhiza Extracts Against Covid-19
}

\author{
Mansoureh Nazari \\ Department of Pharmacy, Universitas \\ 17 Agustus 1945 Jakarta, North Jakarta, \\ Jakarta Capital Special Region, \\ Indonesia \\ *email: nazarimansoure@gmail.com
}

\begin{abstract}
Due to its anti-inflammation effect, Glycyrrhiza extract is one of the natural extracts that may potentially combat coronavirus disease in 2019 (COVID-19). In the current article, we evaluate in silico (molecular docking) properties of active compounds available in Glycyrrhiza, native to Western Asia, North Africa, and Southern Europe, and compare its anti-inflammation effect with remdesivir as positive compounds based on molecular docking characteristics. The main active compounds were selected based on their significant roles in the pharmacological effects of Glycyrrhiza. The results obtained in this study demonstrated that most of the studied main compounds interacted stronger than selected remdesivir to inhibit the spike protein in COVID-19. The combined scores (binding affinity and druglikeness properties of the ligand, demonstrated to be the potentially possible COVID-19 inhibitor compared with positive control. The active site analysis of the interactions also showed that Glycyrrhiza extract containing active compounds might have therapeutic effects against COVID-19.
\end{abstract}

Received: December $18^{\text {th }}, 2021$

Accepted: December 23rd, 2021

Published: December 30th, 2021
Keywords:

Anti-inflammation

COVID-19

Glycyrrhiza

Licorice

Molecular docking
(C) 2021 Mansoureh Nazari. Published by Institute for Research and Community Services Universitas Muhammadiyah Palangkaraya. This is an Open Access article under the CC-BY-SA License (http://creativecommons.org/licenses/by-sa/4.0/). DOI: https://doi.org/10.33084/jmd.v1i2.3154

\section{INTRODUCTION}

COVID-19 pandemic has emerged to be an unexpected medical crisis worldwide. SARS-CoV-2 is investigated to have more infectious properties compared with MERS-CoV1. Its spread rate is very high worldwide. It has affected more than 239 million people worldwide until now ${ }^{2}$. World Health Organization (WHO) suggested the administration of remdesivir as an emergency medicine in a critical stage of infected patients ${ }^{3}$.

Present SARS-CoV-2 virus is approximately $80 \%$ similar to SARS-CoV from the point of genome structure ${ }^{4}$. Coronavirus is a single-stranded RNA virus that is spherical. They have been characterized into four groups: alpha, beta, gamma, and delta types. Gamma and delta types of coronaviruses are hostdependent. However, alpha and beta types of the virus include human and local pathogens that are anticipated to be related to transmission in cross- species,5.6. SARS-CoV and MERS-CoV are considered in the beta genus of coronavirus. They are related to a severe respiratory tract infection resulting in $10 \%$ and $35 \%$ of mortality rates ${ }^{7,8}$.

The SARS-CoV target spike protein with PDB ID of $6{\mathrm{M} 0{ }^{9}}^{9}$ is one of the targets that researchers are intended to discover small molecules to inhibit. It is one of the recognized targets that has attracted many researchers worldwide to predict using computeraided drug discovery ${ }^{10,11}$. They aim to construct novel small molecules with the potential to suppress such protein targets in order to battle the COVID-19 virus ${ }^{12}$. The attention to plant extracts and extracted natural compounds in cosmetic formulations is rising. Natural products may significantly advance cosmetics performance since they have cosmetic and therapeutic-like belongings, known as cosmeceutical properties $^{13,14}$. In the family of Leguminosae, the Glycyrrhiza genus includes more than 30 different 
species, extensively spread worldwide. The most important clinical plant parts are rhizomes and roots, which are presently used in pharmaceutical manufacturing and the food industry ${ }^{15}$. A few years ago, the curiosity about potential plant activities in cosmetic formulations significantly increased. Glycyrrhiza spp. extracts are extensively employed in cosmetic products for their optimum whitening effects $^{16}$. The pharmacological effects of Glycyrrhiza extracts are specifically referable to the incidence of specialized metabolites which belong to the class of flavonoids. Three main flavonoids are highlighted in glycyrrhiza: licochalcone A, glabridin, and dehydroglyasperin $C^{17,18}$. Furthermore, licorice extract showed the best anti-inflammation effects compared with positive control drug in an in vivo model investigation in mice ${ }^{19}$. It is believed this study will help to evaluate the possible pharmacological effects of licorice's main flavonoids to inhibit the sets of amino acids needed for the interactions at the active pocket of target protein in SARS-CoV-2.

\section{METHOD}

\section{Hardware and Software}

The hardware and software used were the same as those reported by a previous study ${ }^{20}$. Python language was downloaded from www.python.com, Molecular Graphics Laboratory (MGL) tools software was downloaded from http://mgltools.scripps.edu, PyRx version 0.8 was downloaded from https://pyrx.sourceforge.io/, BIOVIA draw and Discovery studio visualizer 2017 were downloaded from http://accelrys.com.

\section{Ligands}

The identified structures of active flavonoids were downloaded from PubChem. Discovery studio visualizer was used to convert sdf format to PDB and further used for docking studies. The starting structures of the protein were prepared using AutoDock Tools. Water molecule was deleted, polar hydrogen and Kollman charges were added to the protein starting structure. The starting structure for all the ligands consisting of dehydroglyasperin C (PubChem CID 480775), glabridin (124052), licochalcone A (5318998), and remdesivir (121304016) was constructed using BIOVIA draw. Remdesivir was chosen as positive controls. Their structures were provided from the PubChem website (https://pubchem.ncbi.nlm.nih.gov/). Gasteiger charges were assigned into optimized ligands using AutoDock Tools.

\section{Receptors}

Three-dimensional crystal structure of SARS-CoV-2 target Spike protein with PDB ID: 6M0J9 was nominated and downloaded from Protein Data Bank (https://www.rcsb.org/) (Figure 1). The complexes bound to the receptor molecule, all the non-essential water molecules and heteroatoms were deleted, and ultimately hydrogen atoms were added to the receptor molecule using ArgusLab ${ }^{21}$.

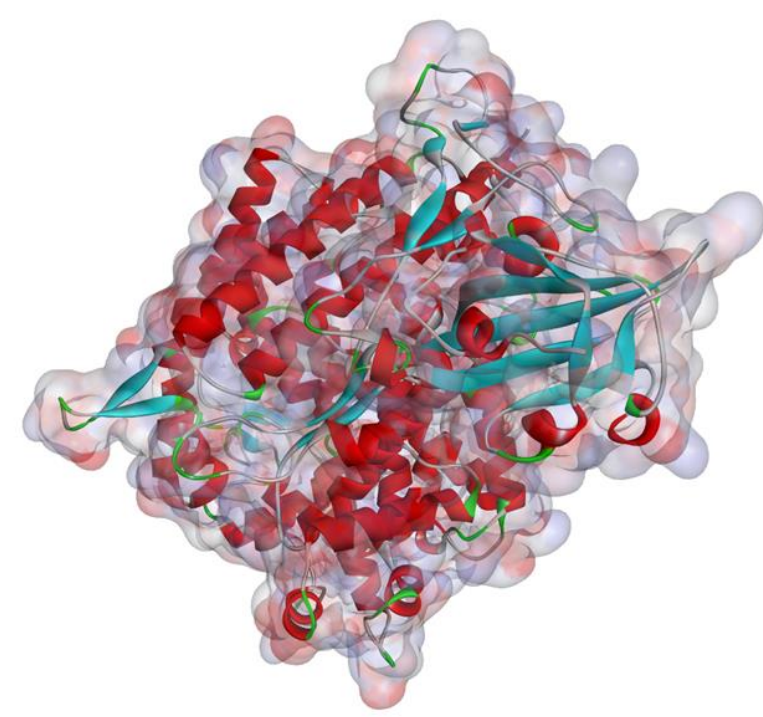

Figure 1. SARS-CoV-2 protein Spike with PDB ID: 6M0J.

\section{Docking Protocol}

The grid box was set with the size of $126 \times 126 \times 126 \AA$ with the grid spacing of $0.375 \AA$ at the binding site. One hundred fifty docking runs were conducted with a mutation rate of 0.02 and a crossover rate of 0.8 . The population size was set to use 250 randomly placed individuals. Lamarckian genetic algorithm was used as the searching algorithm with a translational step of $0.2 \AA$, a quaternion step of $5 \AA$, and a torsion step of 5 $\AA^{22}$.

\section{Assessment}

The parameters used in assessing and ranking the test ligands of the docking results were evidently stated.

\section{RESULTS AND DISCUSSION}

The docked conformation of spike protein, with the active conformation consisting of dehydroglyasperin 
C, glabridin, licochalcone A, and remdesivir, clearly discovered numerous potential interactions were present. The docking results demonstrated dehydroglyasperin $C$ with a free energy of binding $(\Delta \mathrm{G})$ of $-8.3 \mathrm{kcal} / \mathrm{mol}$ after interaction with spike protein. It showed four hydrogen bonds with ASP367, ASN290, ILE291, and THR434; three alkyl bonds with PRO415, LYS441, and MET366; and one Pi-Pi T shaped bond with PHE438 (Figure 2).
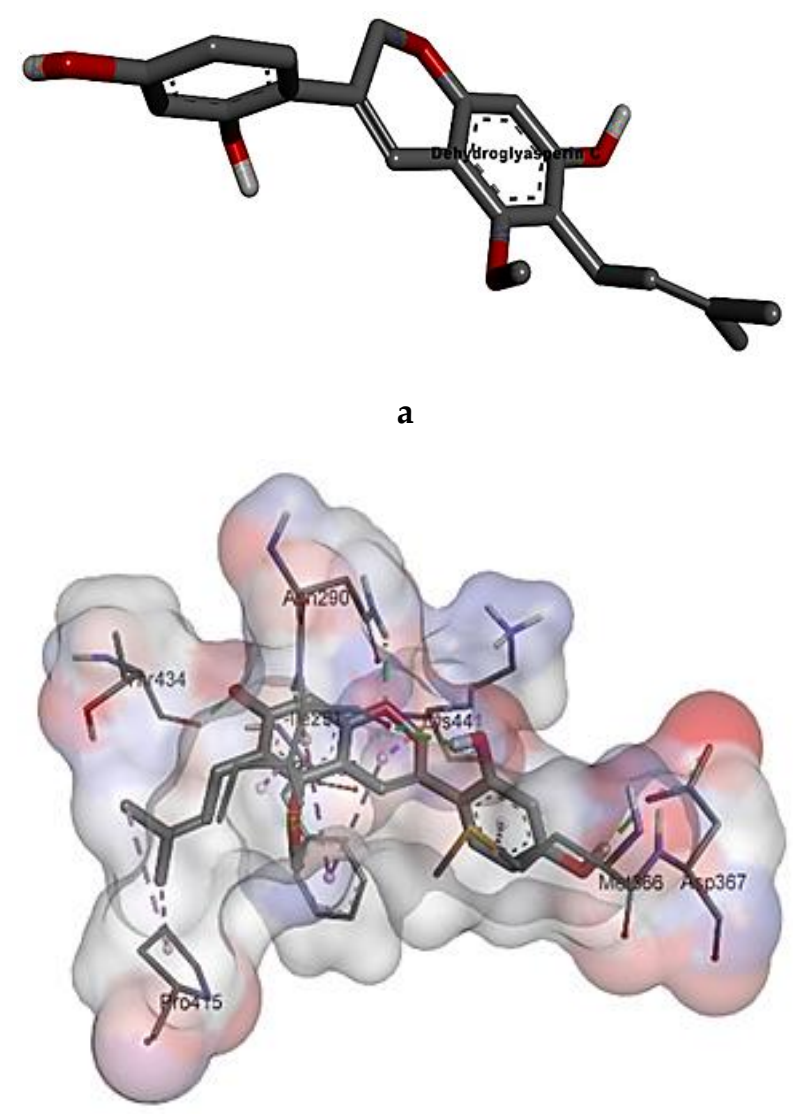

b

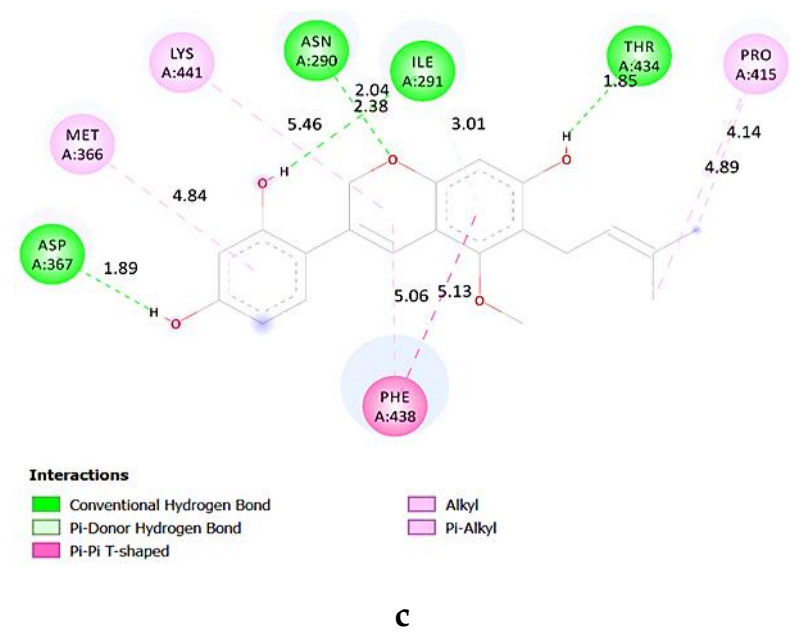

Figure 2. The 3D structure of the compound (a) and the 3D (b) and $2 \mathrm{D}(\mathrm{c})$ interactions between dehydroglyasperin $\mathrm{C}$ and the SARS-CoV-2 spike protein.
Glabridin, after interaction with spike protein, demonstrated four hydrogen bonds with GLU208, TYR196, GLN98, and ASN210, as well as five alkyl bonds with PRO565, VAL212, VAL209, LEU95, and LEU91 (Figure 3). It showed $\Delta \mathrm{G}$ of $-8.46 \mathrm{kcal} / \mathrm{mol}$, the lowest among all the studied compounds compared with remdesivir.

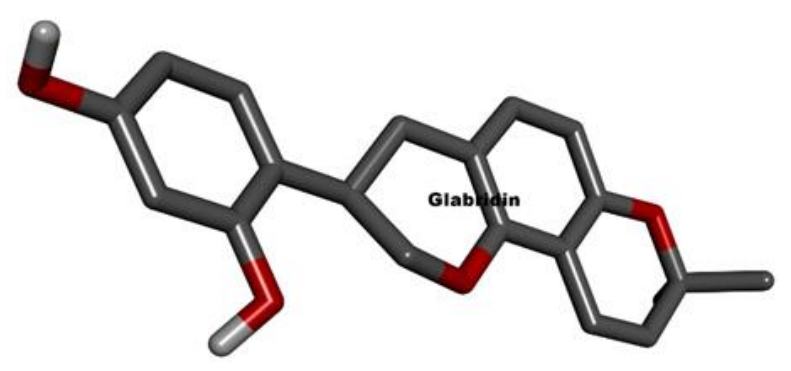

a

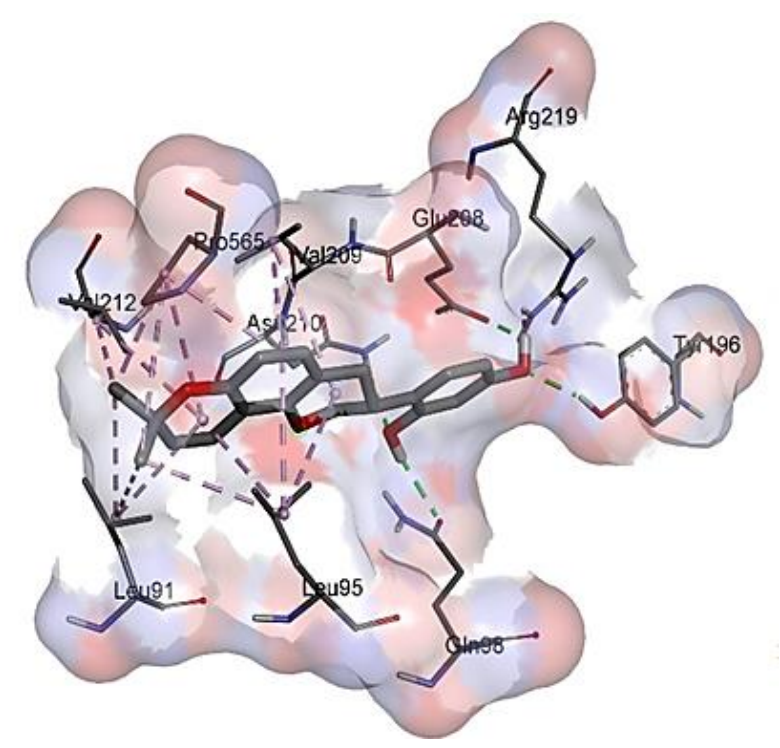

b

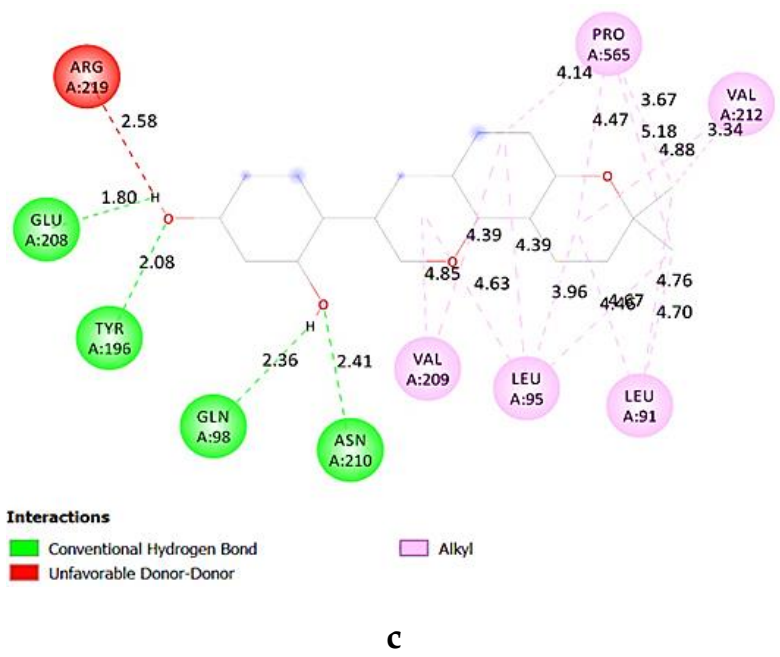

Figure 3. The 3D structure of the compound (a) and the 3D (b) and 2D (c) interactions between glabridin and the SARS-CoV-2 spike protein. 
Licochalcone A demonstrated $\Delta \mathrm{G}$ of $-8.37 \mathrm{kcal} / \mathrm{mol}$ after interaction with spike protein. It showed conventional hydrogen bonds with ASP206, TRP566, and ASN210; pi sigma bond with LEU95; and three alkyl bonds with LEU91, VAL212, and PRO565 (Figure 4).

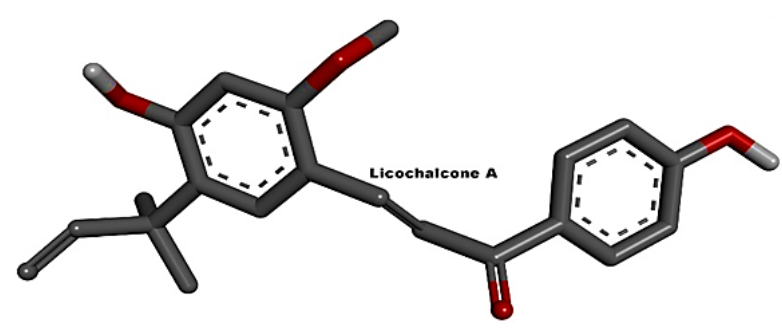

a

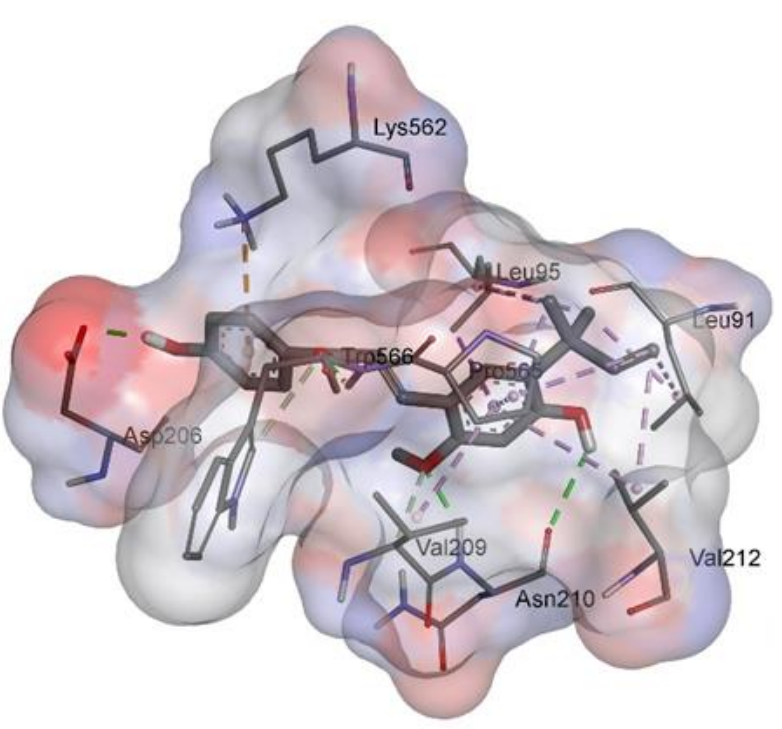

b

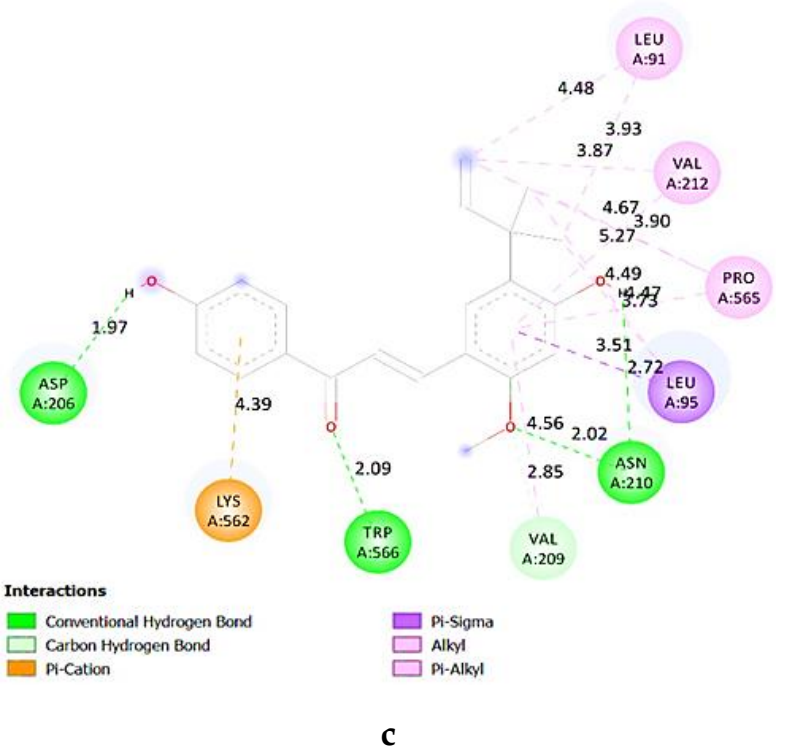

Figure 4. The 3D structure of the compound (a) and the 3D (b) and 2D (c) interactions between licochalcone A and the SARS$\mathrm{CoV}-2$ spike protein.
Remdesivir, as the second chosen standard approved recommended drug for COVID-19, showed three hydrogen bonds with ALA348, ASP382, and TYR385, as well as two alkyl bonds with LEU359 and VAL343 (Figure 5). Moreover, it showed $\Delta \mathrm{G}$ of $-5.97 \mathrm{kcal} / \mathrm{mol}$.

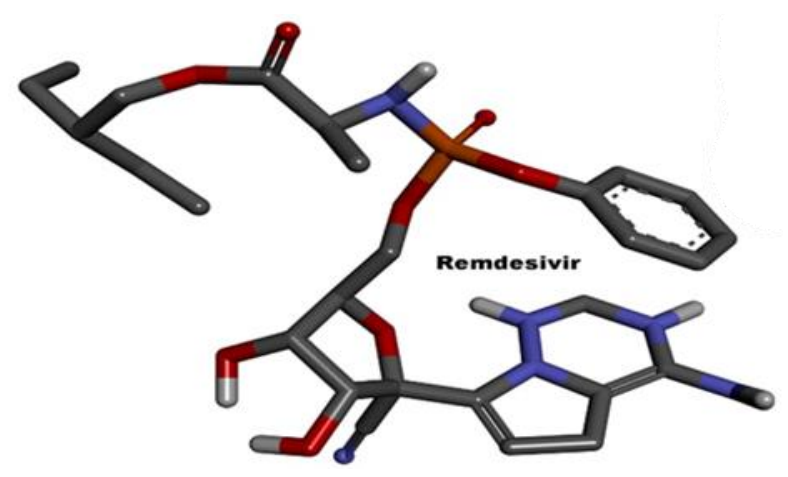

a

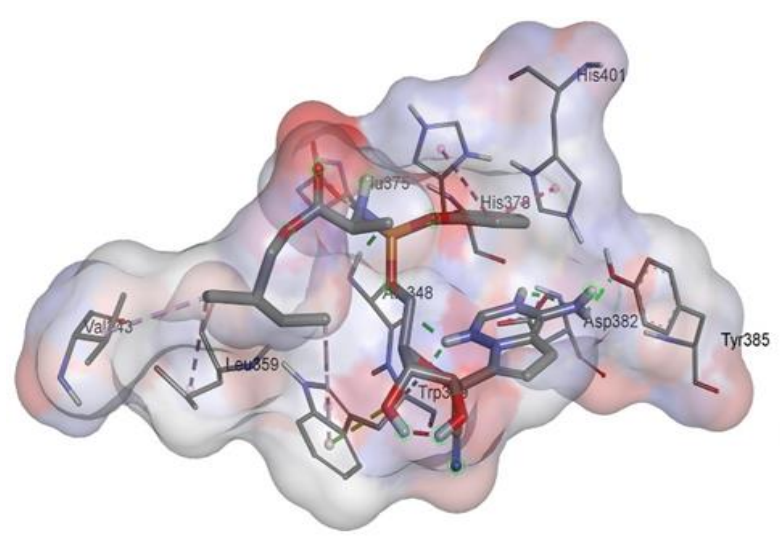

b

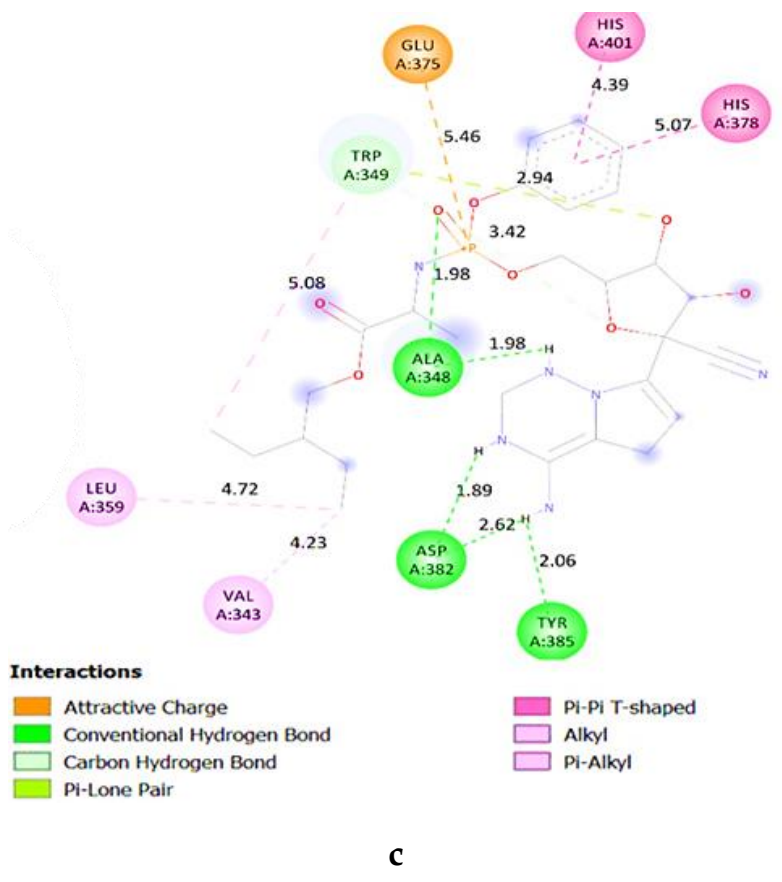

Figure 5. The 3D structure of the compound (a) and the 3D (b) and 2D (c) interactions between remdesivir and the SARSCoV-2 spike protein. 
The interaction between glabridin and spike protein with four hydrogen bonds showed the highest affinity among all other flavonoids and remdesivir as a positive control. However, dehydroglyasperin C showed four hydrogen bonds but demonstrated less affinity towards spike protein compared with licochalcone A. Licochalcone A formed a pi sigma bond in the protein's active pocket hyperconjugation, bending (tilting) of molecular structure ${ }^{23}$. It probably enhanced the ligand and receptor binding, and even though licochalcone A formed three hydrogen bonds but the whole affinity of the system towards studied protein was more than dehydroglyasperin C. Moreover, ASN210 in the structure of spike protein in interaction with licochalcone $\mathrm{A}$ is located in a way that caused two hydrogen bonds with the hydrogen of phenolic group and oxygen of ketonic group in the structure of licochalcone A. it causes a conjugation in the system and electrons can circulate in this conjugation results in a more stable system. This probably can explain the more stability and higher affinity of licochalcone A compared with dehydroglyasperin $C$ in interaction with spike protein. The results of this study also confirm various previous in silico studies, which also identified metabolites from the genus Glycyrrhiza as inhibitors of the SARS-CoV2 spike protein, complementing another study with the same plant against other targets such as the main protease of SARS-CoV-2.

\section{CONCLUSION}

Molecular docking assessment of the main identified flavonoids in Glycyrrhiza extract against spike protein of SARS-CoV-2 has been performed. All of the studied ligands' score binding affinity were better than the remdesivir (lower than $-5.97 \mathrm{kcal} / \mathrm{mol}$ ). However, based on the combined scores of binding affinities and the similarity of the ligands' drug profile, glabridin was the best potential inhibitor of the evaluated spike protein of the COVID-19 virus. Moreover, the active site analysis reveals that ASN210, PRO565, and LEU91 are among the most important amino acids due to their common occurrence in the ligand-protein interaction. Furthermore, since in Glycyrrhiza extract, surprisingly all the studied flavonoids are available so their synergistic effect may have more potential to inhibit spike protein of COVID-19 and may have more potential to be used for its treatment.

\section{CONFLICTS OF INTEREST}

The authors declare that there are no conflicts of interest.

\section{FUNDING}

None.

\section{DATA AVAILABILITY}

All the raw data on the results of research that the authors upload independently both on the open access repositories and other sources are available.

\section{ACKNOWLEDGMENTS}

None.

\section{AUTHORS' CONTRIBUTIONS}

Mansoureh Nazari: conceptualization, data curation, formal analysis, investigation, methodology, project administration, resources, software, validation, visualization, writing - original draft, writing - review \& editing.

\section{REFERENCES}

1. Zhu Z, Lian X, Su X, Wu W, Marraro GA, Zeng Y. From SARS and MERS to COVID-19: a brief summary and comparison of severe acute respiratory infections caused by three highly pathogenic human coronaviruses. Respir Res. 2020;21(1):224. doi:10.1186/s12931-020-01479-w

2. Jayaweera M, Perera H, Gunawardana B, Manatunge J. Transmission of COVID-19 virus by droplets and aerosols: A critical review on the unresolved dichotomy. Environ Res. 2020. 188:109819. doi:10.1016/j.envres.2020.109819

3. Reddy OS, Lai WF. Tackling COVID-19 Using Remdesivir and Favipiravir as Therapeutic Options. Chembiochem. 2021;22(6):939-48. doi:10.1002/cbic.202000595

4. Nguyen TT, Pathirana PN, Nguyen T, Nguyen QVC, Bhatti A, Nguyen DC, et al. Genomic mutations and changes in protein secondary structure and solvent accessibility of SARS-CoV-2 (COVID-19 virus). Sci Rep. 2021;11(1):3487. doi:10.1038/s41598-021-83105-3 
5. Shang J, Han N, Chen Z, Peng Y, Li L, Zhou H, et al. Compositional diversity and evolutionary pattern of coronavirus accessory proteins. Brief Bioinform. 2021;22(2):1267-78. doi:10.1093/bib/bbaa262

6. Li H, Liu SM, YU XH, Tang SL, Tang CK. Coronavirus disease 2019 (COVID-19): current status and future perspectives. Int J Antimicrob Agents. doi:10.1016/j.ijantimicag.2020.105951

7. Pal M, Berhanu G, Desalegn C, Kandi V. Severe Acute Respiratory Syndrome Coronavirus-2 (SARS-CoV-2): An Update. Cureus. 2020;12(3):e7423. doi:10.7759/cureus.7423

8. Petrosillo N, Viceconte G, Ergonul O, Ippolito G, Petersen E. COVID-19, SARS and MERS: are they closely related? Clin Microbiol Infect. 2020;26(6):729-34. doi:10.1016/j.cmi.2020.03.026

9. Lan J, Ge J, Yu J, Shan S, Zhou H, Fan S, et al. Structure of the SARS-CoV-2 spike receptorbinding domain bound to the ACE2 receptor. Nature. 2020;581(7807):215-20. doi:10.1038/s41586020-2180-5

10. Sachdeva C, Wadhwa A, Kumari A, Hussain F, Jha P, Kaushik NK. In silico Potential of Approved Antimalarial Drugs for Repurposing Against COVID-19. OMICS. 2020;24(10):568-80. doi:10.1089/omi.2020.0071

11. Schütz D, Ruiz-Blanco YB, Münch J, Kirchhoff F, Sanchez-Garcia E, Müller JA. Peptide and peptidebased inhibitors of SARS-CoV-2 entry. Adv Drug Deliv Rev. 2020;167:47-65. doi:10.1016/j.addr.2020.11.007

12. Nazari MV, Nazari M, Arabani S, Nazari MV. Anti-Inflammation Prediction of Orthosiphon Stamineus Extract Against Covid19 (In Silico Study). Int J Eng Technol Sci. 2021;8(1):14-8. doi:10.15282/ijets.8.1.2021.1002

13. Hoang HT, Moon JY, Lee YC. Natural Antioxidants from Plant Extracts in Skincare Cosmetics: Recent Applications, Challenges and Perspectives. Cosmetics. 2021;8(4):106. doi:10.3390/cosmetics8040106

14. Faccio G. Plant Complexity and Cosmetic Innovation. iScience. 2020;23(8):101358. doi:10.1016/j.isci.2020.101358
15. Sharifi-Rad J, Quispe C, Herrera-Bravo J, Belén LH, Kaur R, Kregiel D, et al. Glycyrrhiza Genus: Enlightening Phytochemical Components for Pharmacological and Health-Promoting Abilities. Oxid Med Cell Longev. 2021;2021:7571132. doi:10.1155/2021/7571132

16. Ciganović P, Jakimiuk K, Tomczyk M, Končić MZ. Glycerolic Licorice Extracts as Active Cosmeceutical Ingredients: Extraction Optimization, Chemical Characterization, and Biological Activity. Antioxidants. 2019;8(10):445. doi:10.3390/antiox8100445

17. Wang C, Chen L, Xu C, Shi J, Chen S, Tan M, et al. A Comprehensive Review for Phytochemical, Pharmacological, and Biosynthesis Studies on Glycyrrhiza spp. Am J Chin Med. 2020;48(1):17-45. doi:10.1142/s0192415x20500020

18. Ashraf K, Sultan S, Adam A. Orthosiphon stamineus Benth. is an Outstanding Food Medicine: Review of Phytochemical and Pharmacological Activities. J Pharm Bioallied Sci. 2018;10(3):109-118. doi:10.4103/jpbs.jpbs_253_17

19. Zhang Y, Xu Y, Zhang L, Chen Y, Wu T, Liu R, et al. Licorice extract ameliorates hyperglycemia through reshaping gut microbiota structure and inhibiting TLR4/NF-kB signaling pathway in type 2 diabetic mice. Food Res Int. 2022;153:110945. doi:10.1016/j.foodres.2022.110945

20. Habib A, Nazari MV, Iqbal MA, Bhatti HN, Ahmed MBK, Majid AMSA. Unsymmetrically substituted benzimidazolium based Silver(I)-Nheterocyclic carbene complexes: Synthesis, characterization and in vitro anticancer study against human breast cancer and colon cancer. J Saudi Chem Soc. 2019;23(7):795-808. doi:10.1016/j.jscs.2019.03.002

21. Badroon N, Majid NA, Al-Suede FSR, Nazari MV, Giribabu N, Majid AMSA, et al. Cardamonin Exerts Antitumor Effect on Human Hepatocellular Carcinoma Xenografts in Athymic Nude Mice through Inhibiting NF- $\kappa \beta$ Pathway. Biomedicines. 2020;8(12):586. doi:10.3390/biomedicines8120586

22. Mojiri A, Zhou JL, Nazari MV, Rezania S, Farraji H, Vakili M. Biochar enhanced the performance of microalgae/bacteria consortium for insecticides removal from synthetic wastewater. Process Saf Environ Prot. 2022;157:284-96. doi:10.1016/j.psep.2021.11.012 
23. Erol M, Celik I, Kuyucuklu G. Synthesis, Molecular Docking, Molecular Dynamics, DFT and Antimicrobial Activity Studies of 5-substituted-2(p-methylphenyl)benzoxazole Derivatives. J Mol Struct. 2021;1234:130151. doi:10.1016/j.molstruc.2021.130151

24. Li J, Xu D, Wang L, Zhang M, Zhang G, Li E, et al. Glycyrrhizic Acid Inhibits SARS-CoV-2 Infection by Blocking Spike Protein-Mediated Cell Attachment. Molecules. 2021;26(20):6090. doi:10.3390/molecules26206090

25. Diomede L, Beeg M, Gamba A, Fumagalli O, Gobbi M, Salmona M. Can Antiviral Activity of Licorice Help Fight COVID-19 Infection? Biomolecules. 2021;11(6):855. doi:10.3390/biom11060855
26. Sinha SK, Prasad SK, Islam MA, Gurav SS, Patil RB, AlFaris NA. Identification of bioactive compounds from Glycyrrhiza glabra as possible inhibitor of SARS-CoV-2 spike glycoprotein and nonstructural protein-15: a pharmacoinformatics study. J Biomol Struct Dyn. 2021;39(13):4686-700. doi:10.1080/07391102.2020.1779132

27. Srivastava V, Yadav A, Sarkar P. Molecular docking and ADMET study of bioactive compounds of Glycyrrhiza glabra against main protease of SARS-CoV2. Mater Today Proc. 2022;49:2999-3007. doi:10.1016/j.matpr.2020.10.055

28. van de Sand L, Bormann M, Alt M, Schipper L, Heilingloh CS, Steinmann E, et al. Glycyrrhizin Effectively Inhibits SARS-CoV-2 Replication by Inhibiting the Viral Main Protease. Viruses. 2021;13(4):609. doi:10.3390/v13040609 